Binghamton University

The Open Repository @ Binghamton (The ORB)

Spring 2015

\title{
Are We Getting Them Out of the Country? The State of Study Abroad Opportunities Within NASPAA Member Programs
}

\author{
Nadia Rubaii \\ Binghamton University--SUNY, nadia.rubaii@binghamton.edu \\ Susan Appe \\ Binghamton University--SUNY, sappe@binghamton.edu \\ Kerry Cook Stamp \\ Binghamton University--SUNY, kstamp@binghamton.edu
}

Follow this and additional works at: https://orb.binghamton.edu/public_admin_fac

Part of the Public Administration Commons

\section{Recommended Citation}

Rubaii, Nadia; Appe, Susan; and Stamp, Kerry Cook, "Are We Getting Them Out of the Country? The State of Study Abroad Opportunities Within NASPAA Member Programs" (2015). Public Administration Faculty Scholarship. 11.

https://orb.binghamton.edu/public_admin_fac/11

This Article is brought to you for free and open access by the Public Administration at The Open Repository @ Binghamton (The ORB). It has been accepted for inclusion in Public Administration Faculty Scholarship by an authorized administrator of The Open Repository @ Binghamton (The ORB). For more information, please contact ORB@binghamton.edu. 


\title{
Are We Getting Them Out of the Country? The State of Study Abroad Opportunities Within NASPAA Member Programs
}

\author{
Nadia Rubaii, Susan Appe, and Kerry Stamp \\ Binghamton University, State University of New York
}

\begin{abstract}
The pressures of globalization in the 21 st century demand public affairs professionals with new competencies, among them the ability to work collaboratively and communicate effectively across national boundaries and cultural differences. International immersion through study abroad has been demonstrated to be an effective means of enhancing global cultural competencies among undergraduate and graduate students in a variety of other professions, but has not previously been examined within the context of public administration or public policy specifically. This article examines the extent to which public affairs programs are providing students with study abroad opportunities. Drawing upon survey and interview data from representatives of the Network of Schools of Public Policy, Affairs, and Administration's member programs, the authors document the status and defining characteristics of study abroad programs in public affairs, identify challenges, and present a series of recommendations.
\end{abstract}

\section{KEYWORDS}

Study abroad, cultural competency, international education, global citizens

If one accepts the globally interdependent nature of public governance in the 21 st century, the increasing internationalization of academic public affairs programs makes sense. This effort can and does take many forms (Devereux \& Dunning, 2011; Murphy \& Meyer, 2012). In addition to faculty exchanges and curriculum development assistance (Devereux \& Dunning, 2001), curriculum content can be expanded to include readings by authors from around the world and assignments with an international focus, and courses or areas of specialization can be created to allow students to develop greater international or comparative expertise. Class projects can be designed to allow students in one country to work remotely with students in another. Internationalization might also be promoted by diversifying the student body in public affairs programs to include more students from other countries or by inviting international faculty to be guest instructors. All of these strategies are valuable components of internationalization. Our focus in this article is more specifically on study abroad opportunities.

No reliable data exist on the rates of participation in study abroad among public affairs students. This is due to the broad classification system used by the Institute for International Education (e.g., social sciences or management) 
and to the various locations where public affairs departments may be situated within a university. While isolating study abroad participation rates among master's-level public affairs students is not possible with existing data, information on broader trends is available. Between 2001-2002 and 2011-2012, the proportion of master's-level students in the U.S. study abroad population increased from less than $5 \%$ to more than $8 \%$, and participation in study abroad among graduate students in professional schools increased from $1.6 \%$ to $2.6 \%$ (Institute for International Education, 2013).

In addition to the lack of study abroad data specific to the public affairs profession, there is little information on study abroad within the public affairs literature. There is one empirical study of internationalization efforts among the academic members of the Association for Public Policy and Management (APPAM), conducted in 2001 (Devereux \& Dunning, 2001); a case study of the internationalization efforts of DePaul University (Murphy \& Meyer, 2012); and an advocacy piece on the importance of study abroad for Master of Public Administration (MPA) students (Ryan, 2010). While few in number, these sources provide guidance for this research, and specifically related to the level of international engagement, the types of internationalization activities, and the motivations and obstacles for pursuing internationalization. In this study, we pose this main question: To what extent and in what ways are study abroad opportunities being provided to MPA/Master of Public Policy (MPP) students enrolled in member programs of the Network of Schools of Public Policy, Affairs, and Administration (NASPAA)? Drawing upon both survey and interview data, we provide baseline data on the status of study abroad programming within the NASPAA community and provide initial recommendations for public affairs faculty and program administrators.

\section{STUDY ABROAD: LITERATURE REVIEW}

Immersive international experience is widely recognized as an effective strategy to help students recognize their biases, develop appreciation for different cultures and contexts, and build skills in effective intercultural communication (Ballestas \& Roller, 2013; Cheney,
2001; Crowne, 2008; Deardorff, 2006), and to help produce global citizens (Dolby, 2007; Douglas \& Jones-Rikkers, 2001; Horn \& Fry, 2013). As Ryan (2010) effectively articulated, "future administrators benefit greatly from nonU.S. experience," and therefore "we need to get them off campus and out of the country" to develop their intercultural competencies (p. 308).

Empirical and anecdotal evidence suggests that study abroad programs are effective in enhancing students' appreciation and respect for diversity. Undergraduate students from the United States who participate in study abroad emerge more reflective of their own national identity and more appreciative of their role as global citizens (Dolby, 2007). In comparison to other pedagogies, study abroad programs are the most effective means of advancing students' acquisition of cultural intelligence (Crowne, 2008) as well as of intercultural competencies (Deardorff, 2006; Steir, 2003).

Evidence shows that study abroad as a tool for developing cultural competence is most effective when students travel to countries very different from their home country (Crowne, 2008; Douglas \& Jones-Rikkers, 2001; Zhai \& Scheer, 2002). However, Western Europe continues to be the most popular regional destination for U.S. students studying abroad (Institute for International Education, 2013). Other regions of the world are slowly but steadily growing in popularity. Between 2000 2001 and 2011-2012, the percentage of U.S. students studying abroad in Europe fell from $63 \%$ to $53 \%$, while the percentage of U.S. students studying within Africa, Latin America, and the Middle East grew by more than $1 \%$ in each region, and the percentage studying in Asia grew by more than 6\% (Institute for International Education, 2013).

While little is known about study abroad programs in public affairs education, within other fields of professional graduate education, study abroad is being incorporated into the curriculum in recognition of the need to prepare students for the forces of globalization. Business, engineering, social work, and nursing, for example, have all taken steps to 
internationalize their curricula and pedagogy through increased study abroad opportunities, and have documented the benefits. There is growing acceptance that business graduates need cross-cultural competency to be effective managers in the globalizing world and that study abroad is the means to achieve that goal (Cheney, 2001; Marcotte, Desroches, \& Poupart, 2007). Business students who study abroad have a level of "worldmindedness" greater than their counterparts who do not participate (Douglas \& Jones-Rikkers, 2001), have more internationally focused career goals (Orahood, Kruze, \& Pearson, 2004), and are more culturally aware (Black \& Duhon, 2006).

In the engineering field, study abroad is presented as a way to help future engineers bridge differences in defining problems and developing solutions (DiBiaso \& Mello, 2004; Downey et al., 2006). Study abroad has been found to positively influence intercultural development among students in a teacher education degree program (Marx, 2011) and contribute to values development among social work students (Lindsey, 2005). In nursing programs, study abroad is used as a teaching strategy to increase confidence (Long, 2012) and safety (Mkandawire-Valhmu \& Doering, 2012) when working with diverse groups of patients, and to promote greater cultural sensitivity (Ruddock \& Turner, 2007) and cultural competence (Ballestas \& Roller, 2013). Agricultural students who studied abroad were more aware of and open to cultural diversity and had more favorable attitudes toward their respective host countries following their study abroad experience (Zhai \& Scheer, 2002).

\section{RESEARCH METHODS}

Our focus in this article is on study abroad opportunities for MPA/MPP students in NASPAA member programs. We further narrowed our focus to study abroad opportunities that are at least in part administered by the MPA/MPP program (what we label here in-house programs), with specific attention to this question: To what extent and in what ways are study abroad opportunities being provided to MPA/MPP students enrolled in NASPAA member programs? Several sub-questions are addressed: What are the characteristics of these study abroad programs? Why and how were study abroad programs in NASPAA member programs started? What challenges do public affairs study abroad programs encounter?

This research is exploratory, as it seeks to discover ideas and insights about study abroad programming in the field of public affairs. Because of the exploratory nature of the research, data were collected using a sequential mixed methods approach, collecting quantitative data first, followed by qualitative data collection for more detailed exploration (Creswell, 2003). The two-stage process involved an electronic survey administered during October 2013, and follow-up interviews conducted via phone or Skype in February and March 2014. The data collection combined closed-ended questions on the survey and open-ended questions with probes as part of semi-structured interviews. This provided us with a balance of comparable data across programs as well as a sense of the richness and unique attributes of the individual programs.

Using the membership list maintained by NASPAA, e-mails were sent to 275 program representatives $^{1}$ with a brief explanation of the research purpose and a link to a seven-question survey instrument (see Appendix A). Completed surveys were received from representatives of 140 unique institutions, representing a 51\% response rate. In terms of degrees offered and location of the programs (in the United States or other countries), the profiles of the 140 institutions responding to the survey, as well as the group of institutions that offers study abroad opportunities and the smaller group that offers study abroad in-house, all roughly parallel the profile of the general NASPAA membership (see Table 1).

The data in Table 1 suggest that our respondent pool is representative of the broader NASPAA member population and thus our findings can reasonably be generalized.

The survey was designed with skip-question logic to answer basic questions regarding the NASPAA member programs and study abroad opportunities. For those respondents who indicated they offered no study abroad opportunities, the survey skipped to the end and offered 
TABLE 1.

Degree Profile of Public Affairs Programs With Study Abroad Options

\begin{tabular}{|c|c|c|c|c|}
\hline & $\begin{array}{l}\text { NASPAA membership } \\
\text { as of April 2013 } \\
(N=285)\end{array}$ & $\begin{array}{l}\text { Survey } \\
\text { respondents } \\
(n=140)\end{array}$ & $\begin{array}{l}\text { Respondents with } \\
\text { study abroad } \\
\text { option }(n=91)\end{array}$ & $\begin{array}{l}\text { Respondents with } \\
\text { in-house study } \\
\text { abroad ( } n=58)\end{array}$ \\
\hline MPA & $76 \%$ & $82 \%$ & $79 \%$ & $76 \%$ \\
\hline MPP & $10 \%$ & $14 \%$ & $17 \%$ & $26 \%$ \\
\hline MPAff & $6 \%$ & $8 \%$ & $9 \%$ & $9 \%$ \\
\hline Other degree & $16 \%$ & $18 \%$ & $22 \%$ & $19 \%$ \\
\hline Non-U.S. programs & $3.9 \%$ & $5.7 \%$ & $5.5 \%$ & $8.6 \%$ \\
\hline
\end{tabular}

Notes. NASPAA $=$ Network of Schools of Public Policy, Affairs, and Administration. MPA $=$ Master of Public Administration. MPP $=$ Master of Public Policy. MPAff = Master of Public Affairs. Totals exceed 100\% because some NASPAA members offer more than one master's degree.

a thank-you message. For those respondents who indicated that they offered study abroad opportunities for their Masters students, we further probed to discover whether any were run entirely or in part within the program (as opposed to being run by a central international programs office or another academic program) and requested further descriptive data.

In Stage 2 of the research, respondents who reported offering study abroad opportunities at least partially provided in-house were asked to provide names and contact information for those individuals with the greatest knowledge of and responsibility for the programs. Individuals designated by survey respondents were initially contacted by one of the researchers via e-mail during the week of January 27-31, 2014 , with a request to schedule a phone or Skype interview during the period of February 17-28, 2014. Follow-up e-mails were sent in late February and early March, and the last interview was conducted on March 18, 2014. Ultimately, we conducted interviews with 50 individuals from 44 NASPAA programs; each interview lasted 20 to 45 minutes.

Given the exploratory nature of the research, the interviews used largely open-ended questions and provided the opportunity for interviewees to elaborate on their study abroad programs in a semi-structured format. (See Appendix B for interview questions.) The questions and probes were guided by the literature and addressed the sub-questions presented earlier regarding program characteristics, how and why they started, and the challenges they have encountered. Each of the three authors conducted two initial interviews as a pretest with the interview protocol. The protocol was then revised to refine question phrasing and add a final openended summary question about lessons learned.

Each researcher transcribed her own notes, and then one of the researchers' graduate assistant aggregated and compiled the transcribed notes in two forms - one organized by question, and the other by university. The two faculty researchers analyzed the qualitative interview data. ${ }^{2}$ Qualitative analysis served to "examin[e] and interpret...data in order to elicit meaning, gain understanding, and develop empirical knowledge" (Corbin \& Strauss, 2008, p. 1) about study abroad programming in public affairs programs. The faculty researchers thematically coded responses to reflect the richness and range of responses. Themes were evaluated by all three authors and independently applied to the data to provide a measure of interrater reliability.

\section{QUANTITATIVE RESULTS AND DISCUSSION}

Roughly two thirds of all respondents $(n=91)$ indicated that their students have study abroad opportunities. Most commonly, the opportu- 
nity was in the form of an option for all students (see Figure 1). In only one program was study abroad a required component for completion of the degree. Among the one third of programs $(n=49)$ that offer no study abroad, $40 \%(n=19)$ are considering developing study abroad options for their students, and 60\% $(n=30)$ have no plans to create such opportunities. Study abroad opportunities are more common among NASPAA-accredited programs.

Earlier research has suggested that internationalization efforts are often linked to program missions (Devereux \& Durning, 2001; Murphy $\&$ Meyer, 2012), and our findings support this relationship. While $37 \%(n=52)$ of all 140 respondents indicated that internationalization is reflected in the mission of their school and program, 45\% $(n=91)$ of those whose program offered study abroad opportunities, and $50 \%(n=29)$ of those with inhouse study abroad opportunities, indicated that it is referenced directly in the mission statement. Some mission statements refer to serving the community, state, nation, and the broader world, whereas others more clearly suggest the importance of an international perspective. Tests of statistical significance using chi square illustrate a relationship between a program having an international reference in the mission statement and offering study abroad opportunities. ${ }^{3}$ Programs with international references in their missions are more likely than those without such references to offer study abroad opportunities. This does not suggest a causal relationship, but simply that programs which demonstrate one indicator of internationalization are also more likely to display the other. Table 2 illustrates the relationship between international references in the school or program mission and study abroad opportunities.

\section{QUALITATIVE RESULTS AND DISCUSSION}

Roughly $40 \%$ of all survey respondents (58 out of 140 ) and $64 \%$ of those offering study abroad opportunities (58 out of 91) have study abroad programs that are run at least partially in-house by faculty and/or staff within their college, school, department, or master's degree programs. We were provided with contact information for 52 of the 58 programs, and we were able to conduct semi-structured interviews with at least one designated person, and sometimes as many as four individuals, from 44 of these 52 programs (85\%). Qualitative data

FIGURE 1.

\section{Study Abroad Options Among Surveyed Public Affairs Programs and by Accreditation Status}

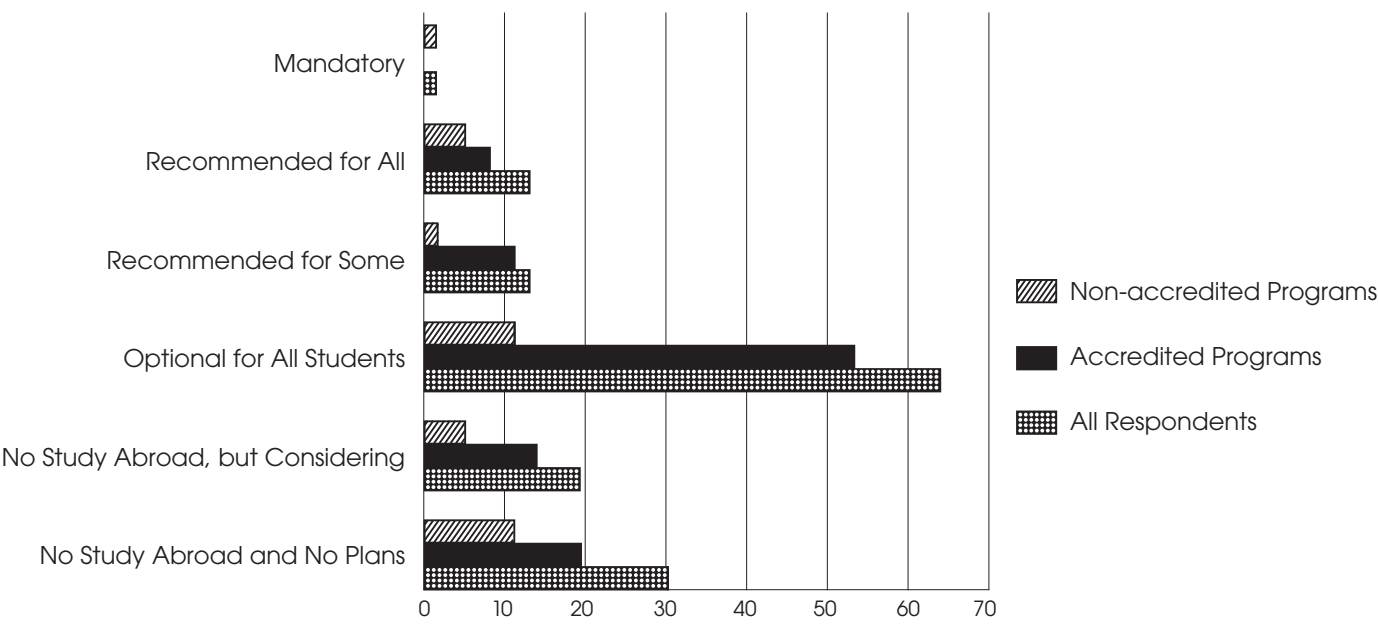

Note. Accreditation status reflects NASPAA accreditation status specifically. 
TABLE 2.

Global Missions in Relation to Study Abroad Opportunities

\begin{tabular}{|c|c|c|c|c|c|c|}
\hline \multirow[t]{2}{*}{$\begin{array}{l}\text { Presence of terms implying } \\
\text { internationalization: }\end{array}$} & \multicolumn{2}{|c|}{$\begin{array}{l}\text { All survey } \\
\text { respondents } \\
(N=140)\end{array}$} & \multicolumn{2}{|c|}{$\begin{array}{l}\text { Respondents with study } \\
\text { abroad opportunities } \\
\qquad(n=91)\end{array}$} & \multicolumn{2}{|c|}{$\begin{array}{l}\text { Respondents with in-house } \\
\text { study abroad programs } \\
(n=58)\end{array}$} \\
\hline & $n$ & $\%$ & $n$ & $\%$ & $n$ & $\%$ \\
\hline $\begin{array}{l}\text { Mission of both school } \\
\text { and program }\end{array}$ & 52 & 37 & 41 & 45 & 29 & 50 \\
\hline Mission of school only & 26 & 19 & 18 & 20 & 13 & 22 \\
\hline Mission of program only & 3 & 2 & 2 & 2 & 1 & 2 \\
\hline Not in mission & 49 & 35 & 23 & 25 & 10 & 17 \\
\hline Unsure & 7 & 5 & 5 & 5 & 3 & 5 \\
\hline No mission exists & 3 & 2 & 2 & 2 & 2 & 4 \\
\hline
\end{tabular}

were gathered through interviews and are the basis for the remaining analysis and discussion. As mentioned earlier, within the broad framework of our research question, we have three sub-questions: (a) What are the characteristics of these study abroad programs? (b) Why and how are study abroad programs in NASPAA member programs started? and (c) What challenges do public affairs study abroad programs encounter? Our discussion is organized around those questions.

\section{Study Abroad Program Characteristics}

Of the 44 programs for which we obtained interviews, the extent of program-based study abroad ranges from a single option to as many as 20 options. We categorize these as falling into one of four categories: (a) direct-enrollment semester or academic year programs (what many of our interviewees referred to as semester exchange), (b) dual degree programs, (c) individualized projects, and (d) short-term programs. The first two types require a university partner in another country; the latter two may or may not involve other universities. Similarly, the first two options always involve courses completed for academic credit, whereas the latter two options may or may not be credit-bearing. Figure 2 illustrates the opportunities in each of these categories. However, it should be noted that some universities offer more than one type of program and many offer several programs within any given category.

The most traditional form of study abroad involves a student spending a semester taking classes through direct enrollment at a university in another country. In some cases, students complete courses at the host institution that have been deemed to be the equivalents of required courses within the home program; more often all or most of the courses taken while out of country are electives. More than a third of 44 programs interviewed $(n=17)$ offered this option to students. The challenge to this study abroad approach is the time required. Many students do not want to disrupt their program of study or leave their jobs for that length of time. Respondents also reported that this form of study abroad may not engage the student fully in the culture and community of the host country if their experience is confined largely to the university campus and interaction with other students.

A much smaller number of programs $(n=4$, representing only $8 \%$ of respondents) have dual degree programs with universities in another country. These programs generally involve one to one and a half years of study at each university to earn master's degrees from both institutions. These programs, while few in number, may have more appeal to pre-service students-who 
are typically younger, full-time students without significant work or family responsibilitiesbecause of the added benefit of an additional degree. Respondents also said that creating these programs required a tremendous commitment of time and energy, even though only a small percentage of students are likely to participate.

A third type of study abroad opportunity provided within master's-level programs in public affairs can be broadly labeled as individualized projects. Programs may allow international capstones, have certificate programs that encourage international activities, or oversee independent study projects designed by students. Six respondents $(13 \%)$ indicated that international individualized projects were a formal part of their program, and several others indicated that they would welcome opportunities to assist students in these endeavors. The locations, scope, and nature of these study abroad programs is inherently diverse and tailored to individual student interests.

The most common form of study abroad programs within public affairs graduate education are short-term programs. This is consistent with general study abroad trends and accommodates in-service students for whom semesterlong study abroad is not feasible. Between 2004 and 2012, short-term programs (those lasting less than 8 weeks) increased from $51 \%$ to $59 \%$ of study abroad options across (Institute for
International Education, 2013). More than $70 \%$ of our survey respondents (representing 33 programs) indicated that they have shortterm study abroad opportunities. Among our respondents, the most common design is a program lasting 2 to 4 weeks with 10 to 20 students. These programs may take the form of cultural tourism, consulting projects, international research labs, or service learning. They may or may not be linked to academic course content, but more than $80 \%$ are credit-bearing. One school reported that "we used to have several exchange programs of full-semester in length but we shifted to short-term because so many of our students work full-time and the longer-term programs had too few participants." One program indicated that about 30\% of their students complete a semester-long study abroad, whereas many more participate in the shorter programs.

The short-term programs are typically offered annually or every 2 years, although 10 schools had at least one country to which they had offered a study abroad opportunity only once, and one program rotates its study abroad opportunities among more than 20 countries to provide variety for students and to engage more faculty. Short-term programs are most frequently scheduled to coincide with the summer or winter intersessions or spring break. Faculty typically lead short-term programs, but in four cases, respondents reported having programs led by

FIGURE 2.

\section{Types of In-House Study Abroad Opportunities Within NASPAA Member Programs}

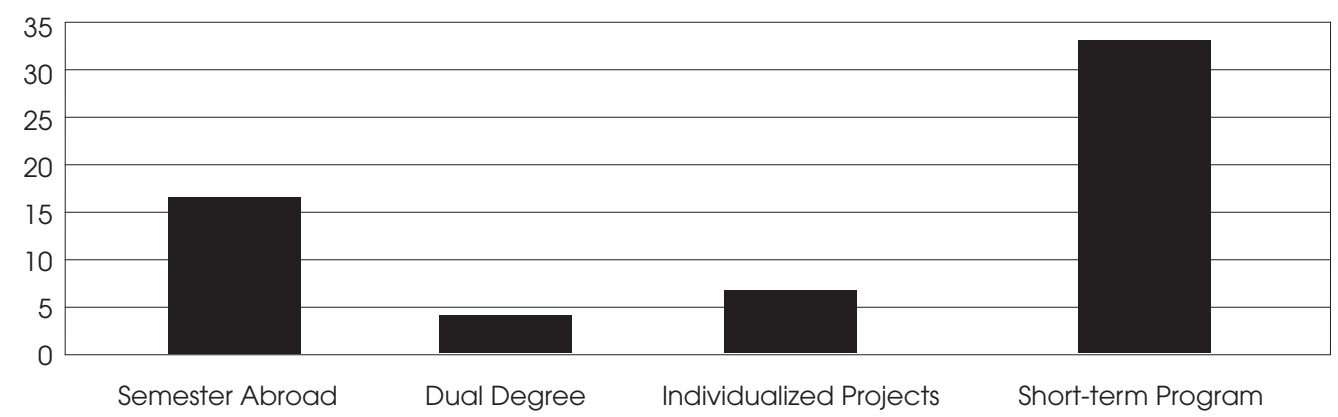


advanced students or alumni, with a faculty member responsible for evaluating work and assigning grades. Six programs require that short-term study abroad have two faculty leaders (or in one case, one faculty and one staff member), and three programs reported university policies requiring that groups be accompanied by one male and one female faculty member.

Relationship With a Central Office. Given our focus on study abroad housed at least in part within an MPA/MPP program, an element of interest in terms of program characteristics and design is that of the relationship between the NASPAA member program and the central university office responsible for study abroad. The names of the central offices vary and in some cases there are multiple offices at a single university. Whether the entity is called the office or center of international programs, internationalization, study abroad, education abroad, international education, or global education, our research suggests that arrangements between the MPA/MPP program and a central unit can be characterized in terms of two dimensions of three categories each. Programs differ in terms of the distribution of responsibilities between the program and the central office (predominantly program, evenly split, or predominantly central office) as well as in the nature of the relationship between those two entities (positive, neutral, or negative). Table 3 shows the distribution along these two dimensions.
When responsibilities are shared, the most common division of labor is that the NASPAA member program handles recruitment, admissions decisions, academic requirements, and in-country logistics, while the central office handles application processing, visas, health insurance, vaccination requirements, collection of tuition and fees, budgeting, and risk management. Less consistently placed in one location or the other are the responsibilities for marketing study abroad opportunities, making travel arrangements (booking flights and arranging lodging), and conducting student orientations; the latter is sometimes a shared responsibility.

Among the programs that we placed in the category of having a positive relationship with the central office, interviewees used phrases such as "we have a collaborative relationship" or "they are very helpful" or "we have a very good and capable international programs office." In the neutral category are those programs that had neither a positive nor negative relationship, such as the one that reported, "We do have a central office, yes. All they really do is hold our signed documents." Another explanation for what we categorized as a neutral relationship is the absence of any relationship. Two of the programs in this category are, in fact, entirely run within the MPA/MPP program with no contact with a central office whatsoever. One program offered by an MPA program outside the United States involves collaboration between programs at three universities in three

\section{TABLE 3.}

\section{Study Abroad Programs' Division of Labor and Relationship Between Department} and Central Office

\begin{tabular}{|c|c|c|c|c|}
\hline & $\begin{array}{c}\text { Predominantly } \\
\text { or exclusively } \\
\text { program }\end{array}$ & $\begin{array}{l}\text { Shared or } \\
\text { evenly split }\end{array}$ & $\begin{array}{l}\text { Predominantly } \\
\text { or exclusively } \\
\text { central office }\end{array}$ & $\begin{array}{l}\text { Row } \\
\text { totals }\end{array}$ \\
\hline Positive relationship & 1 & 4 & 0 & 5 \\
\hline Neutral or mixed relationship & 13 & 20 & 2 & 35 \\
\hline Negative or problematic relationship & 2 & 2 & 0 & 4 \\
\hline Column totals & 16 & 26 & 2 & 44 \\
\hline
\end{tabular}

Note. $n=44$ 
different countries in the region and national government agencies in each country; in this case, there is no role for the central university study abroad office.

When relationships were characterized as negative, the usual reasons cited were differences in philosophy and a sense that the central office was charging too much for its services and pricing study abroad out of the reach of students, that it was overly bureaucratic and focused on regulatory compliance, or that it did not understand the dynamics of study abroad that is designed as international service learning. Among the representative comments for respondents in this category is that "they are perceived of as more of an obstacle than an aid."

Respondents at 12 programs described an evolving relationship, in which faculty had started study abroad programs and initially had almost free rein and complete responsibility for situations for which the central office was now gradually assuming more and more responsibility. Some interviewees saw this as a generally positive trend, whereas others were quite frustrated with the MPA/MPP program's declining autonomy. In explaining this trend, one respondent noted that " 10 years ago everything was done within the college, but increased concerns about liability have led to a shift of more responsibilities to the central office."

There is also considerable diversity of relationships within the category of predominantly program-run opportunities. In some cases, these involve staff of the MPA/MPP program or public affairs school assuming all of the traditional roles of a central office, in other instances an individual faculty member coordinates almost all functions, and in still others many responsibilities are left to the students.

Program Location. In keeping with the literature described earlier regarding study abroad destinations, overall the most common region for in-house study abroad opportunities within public affairs programs is Western Europe (59\%, $n=26)$, followed by Asia $(52 \%, n=23)$, Latin America and the Caribbean (45\%, $n=20)$, and Africa $(30 \%, n=13)$. Fewer than four programs each $(9 \%)$ reported offering opportun- ities in Central or Eastern Europe, Australia or New Zealand, the United States, Canada, the Middle East, or Eurasia (see Figure 3). Most of the responding NASPAA programs that offer in-house study abroad have multiple programs that span several regions of the world; only seven of the respondents (16\%) offered just one program or had programs in only one region. To offer variety that would meet student and faculty interests, more than half of the respondents indicated that they rotate the location of all or some of their programs.

There are some notable relationships between program type and geographic location. Semester exchange and dual degree programs are predominantly, although not exclusively, based in Western Europe, Australia, or New Zealand, or, for the non-U.S. schools, in the United States. In contrast, the short-term study abroad programs are more evenly distributed across all regions. Without exception, interviewees mentioned language as a factor that influenced program decisions; this is discussed later as a challenge for study abroad program development.

\section{Motivations and Processes for Establishing Study Abroad Programs}

Why have some MPA/MPP programs developed study abroad opportunities while others have not? Among the programs included in our analysis, the factors leading to program creation fall into three general categories: faculty interests and initiative, strategic planning, or invitation. For MPA/MPP programs with multiple study abroad programs, each may have had different motivational factors. In some cases it is a combination of forces that creates the window of opportunity to start a new program.

Faculty Interests and Initiative. The single most important factor in determining whether to launch a study abroad program is faculty initiative, with 27 programs (61\%) of the 44 programs interviewed identifying this as the reason for starting at least one of their programs. Faculty rationales ranged from being a native of the country to having a strong personal relationship with someone in a university, government agency, or nongovernmental organization (NGO) in the country; to having research interests in the country; or sometimes simply to 
FIGURE 3.

Number of In-House Study Abroad Programs by Destination Region

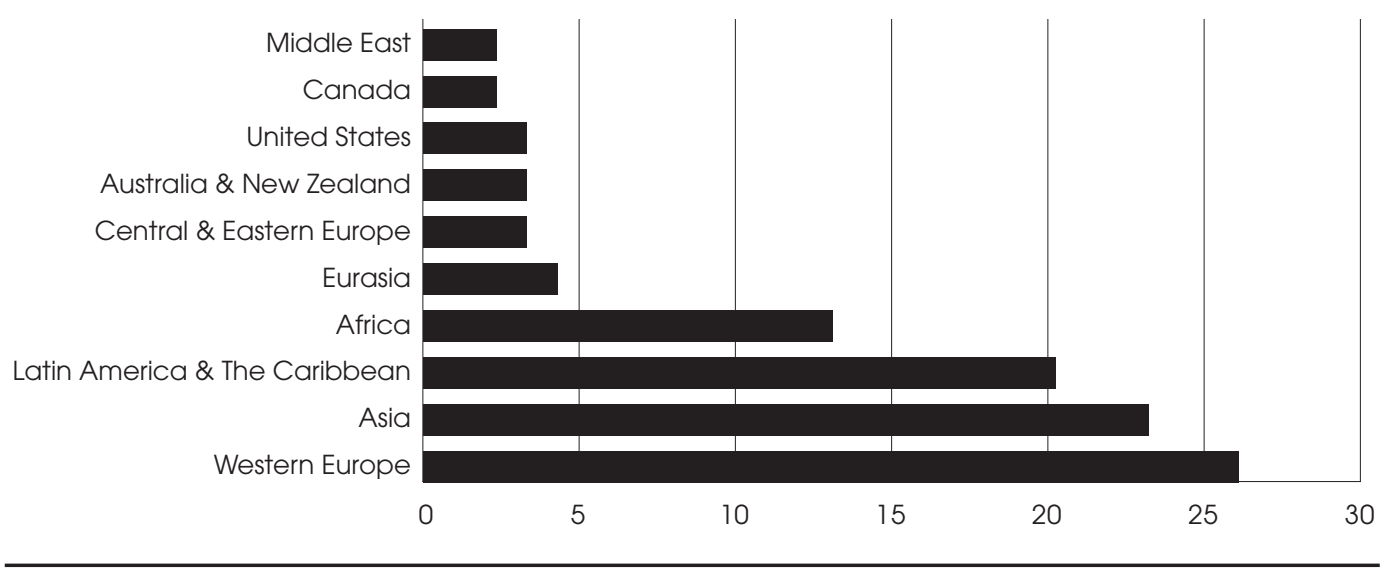

having travel interests in the country. Several study abroad programs were preceded by faculty trips. In one university, among the options for fulfilling core service responsibilities in the department is developing international exchanges and relationships. Typical of the remarks we heard are that "faculty who have international experience and connections within the countries [are] the key to study abroad success," that "it takes faculty interest for programs to start and succeed," and that "the most successful programs are linked to faculty research interests and should be with faculty who have been to that country at least several times, or better yet be a native of that country or have lived there for an extended period."

In addition to research interests and personal connections, faculty are also motivated to start study abroad opportunities because of their individual commitments to this as a means of developing students' cultural competence. One interviewee characterized herself as being "a huge champion of study abroad. It was such a big part of my life and I think it was important." In describing a program to an East African country, one interviewee explained that the program was "developed based on my personal relationships with $\mathrm{NGO}$ and religious leaders in [the country] and a desire to provide students from [my university] with an opportunity to see how the bottom billion people in the world live. Most people from [our state] have no clue." Another faculty member describes having started a program to Mexico to "help demystify the idea that it is impossible to learn a foreign language or that you can't deal with people from abroad." Another program to Mexico was started in response to a growing Latino migrant farmer population surrounding the university and based on the "recognized need to expand student understanding of and appreciation for Hispanic cultures."

Strategic Planning. While not as prevalent as faculty-driven motivations, strategy and planning are not entirely absent from program design decisions. Clear strategic rationales for the creation of one or more of their study abroad opportunities were reported by 17 programs (39\%).

In some cases, the strategic decision simply refers to consciously developing a range of options for students in various parts of the world, which locations may be determined at the program or university level. Universities may prioritize internationalization generally or specific countries and regions. For example, the study abroad program to South Africa at one NASPAA member school is rooted in the long-term university relationship that started in 1987, when many were divesting in South Africa and this university decided that it should be investing in the country instead. The MPA program has been active 
in this study abroad program that supports both faculty and student exchanges. Another program justified its study abroad program to Seoul, South Korea, as being in alignment with its university prioritization of partnerships with Japan, China, Korea, and India.

In some cases, selection of location can be understood as universally important, while in other cases it is more university or program specific. Several respondents indicated that they recently started or are planning to start study abroad programs in China for strategic reasons. In the words of one respondent, "We want to be seen as a truly global program and you can't do that in today's world without being in China." While China may seem like an appropriate strategic study abroad location for many programs, the selection of Ireland for a study abroad program was presented as a strategic selection by a program based in Boston, Massachusetts, where the student population and surrounding community have strong cultural ties to Ireland.

Other respondents reported carefully selecting the "right schools" for exchange and dual degree relationships, based on rankings and prestige as well as on compatibility of missions or areas of emphasis. A leading U.S. MPA program in local government management was strategic in developing a dual degree program with a university in Thailand that also specializes in local government.

Two philosophies about compatibility of curriculum were offered. One interviewee advised programs to "look for a partner institution that offers comparable courses," because "students will get a different perspective simply by being in another country. Even an economics or information technology course with some pretty standard content will be different in that other context of laws, culture, values." In contrast, a respondent from another university advised against "picking schools just like yours," saying that this makes for "easy curricular exchange, but sometimes it is more important to have the same values and objectives and not have the same curriculum, so that they might offer something else to your students, something value-added."
Only one program described a cohesive strategy for all study abroad activities, a strategy based on five criteria: (a) taking students out of their comfort zones to places that are challenging but are also safe, (b) focusing on locations outside of Western Europe, (c) representing diverse regions of the world, (d) aligning with faculty research interests and expertise, and (e) responding to student interests. Based on these criteria, decisions are made about locations for study abroad and then faculty with the relevant expertise, connections, and access within the country are hired. As a result, the school has seven study abroad programs, offered consistently every year, to locations in Argentina, Colombia, South Africa, Uganda, Kosovo, Hong Kong, and Turkey.

Invitation. In some cases it is neither a faculty member nor a high-level strategic decision that drives the creation of a study abroad program, but rather an invitation from an outside party. These invitations may be from governments, universities, or individuals in other countries seeking a partnership. Four separate universities reported having relationships with the Seoul Metropolitan Government (SMG), formed as a result of an invitation to participate and the development of a contractual relationship for several years of study abroad trips. One university with study abroad programs to the Netherlands, Mexico, and Australia established all three programs only because it was approached by others seeking to partner with it. The interviewee described the program's approach as one that "has been and will continue to be wait and see who approaches us." One interviewee from a program outside the United States referenced the importance of the NASPAA network as the basis for starting a study abroad partnership.

Alumni Contacts. A variation on each of the main motivators (faculty initiative, strategic planning, and invitation) involves program alumni. Relationships between faculty and alumni may be the basis for a faculty initiative; alumni who are positioned as faculty or administrators in international universities present logical places for strategic partnerships; and in several instances alumni, either as representatives of universities or working in NGOs or government agencies, invited their alma mater to begin a study abroad program. 


\section{Challenges to In-house Study Abroad Programs in Public Affairs}

The challenges associated with developing, implementing, and sustaining study abroad programming are many. The most prevalent issues that surfaced in our data were language barriers, lack of sufficient resources, and absence of program assessment.

Language. Language appears to be a limiting, driving factor in choosing program locations, with the typical remark being that "language is a barrier." For many schools, language considerations were the basis for locating study abroad programs in Western Europe, where English is generally accessible. Roughly one quarter of respondents said their programs limit study abroad options accordingly, while many others said they have at least some study abroad options that do not require another language.

Some programs to countries where English is not the native language often conduct classes entirely in English. In the case of programs coordinated with the SMG, for example, all sessions are conducted in English, and if government officials speak in Korean, the Seoul government provides instantaneous interpretation services. A program that sends students to Cuba relies on Cuban counterparts who speak English rather than expecting students to speak Spanish. Programs in places as diverse as Korea, Bulgaria, Brazil, Thailand, Turkey, and the United Arab Emirates use a language interpreter to keep things in English for students. In these cases, instructors usually provide a "quick and dirty" introduction of key words and phrases to the students, for whom that is the extent of their language experience.

One MPA/MPP program reported that their U.S. students can study abroad in Germany, Mexico, Japan, Egypt, China, Singapore, and Israel, with no language requirements. Two schools outside the United States, for which English is not the language of instruction, also reported that they have designed study abroad programs with English as the primary language. Where study abroad programs are offered in several locations, some in English and others requiring a second language, interviewees re- ported that the English-speaking programs are more popular, and those that require another language frequently struggle to achieve a critical mass of students. Six interviewees referenced study abroad programs that no longer existed at their institutions because of language barriers. Two specifically mentioned unsuccessful attempts to run programs in Italy; as one put it, "we tried in Italy but the language was tricky."

Not all study abroad programs within public affairs are conducted in English. Some semesterlong study abroad programs inform students of the need for language proficiency and place responsibility on the student or rely on the testing process of the host university to screen for fluency. Three short-term programs with international service learning (ISL) reported having intensive language immersion as part of the international experience. In one case, the faculty leader screens all student applicants himself to ensure Spanish-language proficiency for a service-learning program in Mexico, noting that "not enough language knowledge would burden the organization with which we work." Two ISL programs have intensive language immersion as part of the study abroad program, to learn Spanish or Quechua in Peru and K-Swahili in Tanzania. The three non-U.S. schools interviewed also use a variety of approaches, designing some programs to be in the language of their home country, and others that require students to be functional in another language (in this case, usually English).

In sharp contrast to the overwhelming majority of programs in our study, one school requires all of their students to have a second language and some international experience as a condition of admission, and builds language instruction into the core curriculum for three of the four semesters of the master's program. Another program reported that the faculty are debating whether they should add a language proficiency component for students pursuing a global leadership concentration, which requires individualized international projects.

Resources. The cost of study abroad is prohibitive for many students, and several programs referenced providing scholarships to increase 
accessibility. For short-term programs in which faculty accompany students, someone-either the program or the students-has to cover the faculty expenses. Several programs require that two faculty or one faculty and one staff member accompany the students, so there are additional costs. One interviewee warned, "Don't scrimp on resources. The experience is enhanced when students are fully supported, and you need two faculty to provide this support. It is worth the cost for the quality of the experience."

In addition to the costs in dollars, there is also an investment of time and energy required to create and maintain study abroad programs effectively. One experienced study abroad faculty leader cautioned that "much more planning is required for the curricular component of a study abroad experience because the topics are generally not within the ordinary MPA core and thus there are no prepackaged books." Study abroad courses require "more focused intentionality on the part of the professor to link the specific study abroad experience to the program goals."

Assessment. We were somewhat surprised to find, in a profession that espouses the importance of program evaluation and evidence-based decision making, and which applies accreditation standards based on assessment of learning outcomes and program impact, minimal use of systematic approaches to measuring the success of in-house study abroad opportunities. We also found that this is a challenge to growing and sustaining study abroad programs in the field. More precisely, there is minimal data collection, practically no analysis of the data collected, heavy reliance on anecdotal evidence, and use of standard course evaluations or student grades in classes without adaptation to reflect the unique nature of study abroad goals and objectives.

While 18 of the respondents (41\%) indicated that data on student participation is collected by either the program or the central office of international programs, only two programs (less than 5\%) analyze the data collected. Nearly $60 \%$ of the sample of NASPAA member programs that offer in-house study abroad programs do not collect any data on the rates of participation or the characteristics of participating relative to nonparticipating students. Roughly one quarter of the respondents cited very small sample sizes as the reason for not collecting or analyzing data. These included remarks such as "The small number of participants and individualized nature of the programs doesn't lend itself to formal evaluations" and "We have 300 students and [study abroad] is only affecting $4 \%$. We aren't going to complicate it."

Among those respondents whose programs had sufficient numbers of students and programs over time for analysis, the typical responses included remarks such as "We have basic data, but no one is in charge of analyzing it" or "We can look up the names of people who went" or "No, but this is a really good idea." Other respondents believed data was or may have been collected by the central study abroad office, but there was no sharing of that information with the program. One respondent commented that their department was not deliberately collecting information on their study abroad participants, but "information is collected through the application portal though, so it exists."

When asked how the study abroad programs are evaluated to determine effectiveness or success, the modal response $(n=21,47 \%)$ was that there are no formal evaluations and the program relies on anecdotal evidence and informal feedback from the students. The second most common response $(n=19,43 \%)$ was that standard student course evaluations are used. A smaller proportion of programs used student participation rates as an indicator of popularity $(n=11,25 \%)$ and student performance as measured by course grades as an indicator of program effectiveness $(n=9,20 \%)$. Less commonly used methods of assessing study abroad programs, mentioned by fewer than five respondents each, included student papers or journals (either before and after or simply at the end of the program), student presentations about the experience, debriefing sessions, tailored student surveys, individual student interviews, formal faculty reports, and feedback from partners in the host countries. 
Where respondents reported having tailored course evaluations or additional questions for their study abroad programs, these evaluations tend to gauge both the academic component and nonacademic component. Some ask explicitly about how the international experience influenced the student personally, academically, and professionally. Participation may also be a form of anecdotal evidence in the sense that data are not collected and analyzed but programs are able to see if there is sufficient interest to continue offering a program. As one respondent described it, the "lowest bar of success is participation and the second lowest bar is continued participation. If no one is signing up, we wouldn't call that successful, and if program is increasing in popularity, would suggest that program is effective."

Whether combined with formal methods or used as the sole source of feedback, anecdotal evidence was referenced repeatedly as an important and valuable indicator of program success. Fifteen respondents representing 12 distinct programs indicated that on the shortterm, faculty-led programs, they are able to observe student engagement and reflection. One interviewee characterized the process as "more intuitive than data driven. When you are with a group of students $24-7$ the feedback is immediate and ongoing...Evaluation is more of an art than a science in this context."

\section{IMPLICATIONS AND RECOMMENDATIONS}

Global cultural competencies are essential even if students do not intend to work in organizations that are explicitly global in scope or on policy issues that are specifically international. Study abroad is not the only means by which to provide international experience and enhance global cultural competencies, but it has been demonstrated to be among the most effective methods. In this context, our research identifies several areas which demand our attention as a profession.

Our research finds that more than one third of NASPAA member programs offer no study abroad opportunities, and fewer have opportunities that are designed and managed within the MPA/MPP program specifically for their students and specifically aligned with their program's learning outcomes. Even in the schools that identify international missions and that provide students with in-house study abroad opportunities, only a small percentage of students participate.

No program included in this study reported having a systematic process for evaluating why students choose not to participate, but their comments suggest that the key factors are cost and time considerations and, for those programs not conducted in English, language barriers. Although we did not specifically probe for information on full-time versus part-time student participation, the comments of interview respondents indicated that while participation is low among all students, it is even lower among those who work full-time. If participation is one indicator of success, we need to think not only in terms of attracting a sufficient number of students to keep programs financially viable, but also to increase the proportion of public affairs students taking advantage of the experiences that are offered. To accommodate the schedules of in-service students, we should continue the trend toward development of more short-term programs.

Further exploration through interviews suggested that there is a need to improve access to study abroad for public affairs students. Part of improving access relates to language. Our research indicates the need to expand our linguistic horizons and take responsibility for helping students develop second-language skills at least at a rudimentary level. Given the demonstrated link between language and culture and the value of study abroad in locations distinctly different from our home countries and communities, we should be concerned about an overemphasis on Englishfocused study abroad among U.S. public affairs programs. When this English-language bias is combined with the general imbalance in study abroad participation, in which many more students enter the United States for study abroad than go from the United States to other countries, we are contributing to a future scenario in which public administrators from the United States may be among the least culturally competent actors on the international scene.

Whether a program is able to offer its own inhouse study abroad programs or not, to build 
cultural competency among MPA/MPP students, public affairs faculty have a responsibility to incorporate materials and assignments in their classes to begin to broaden students' perspectives and to foster interest in appropriate study abroad opportunities. As advisors, faculty and staff within public affairs programs can and should speak with students about their interests related to study abroad, assist in the identification and selection of relevant and appropriate programs, and guide students in the process of securing financial support to allow them to participate.

To encourage this, we need to develop strategies to systematically enhance the cultural competencies of all who are involved in public affairs education. If all students need to be globally aware and culturally competent, then faculty and staff should have these competencies as well. Ryan (2010) warned of self-selection biases among study abroad student participants, and a similar caution can be applied to faculty. If international experiences are an effective way to develop and enhance these competencies, we need to encourage greater participation by faculty and commit resources to facilitate this participation. We should consider how we are preparing the next generation of faculty and whether our doctoral programs are promoting these international experiences and cultural competencies.

In addition, MPA/MPP programs need other kinds of resources and investments to administer and sustain in-house study abroad programs. Three interviewees recommended having a staff member in the department to do the work of organizing travel and arranging for student visas. Another suggested recognizing study abroad activities as a faculty service assignment. One program advocated for using students from prior years as a means of reducing recruitment expenses and more effectively communicating with prospective students.

Regardless of whether the methods used to assess study abroad programs were formal and tailored, generic, or largely anecdotal, all interviewees were able to provide illustrative examples of how they have made modifications and improvements to their programs over time. However, there is a need for more thoughtful and comprehensive assessment of study abroad. Notably absent from the assessment of in-house study abroad effectiveness are indicators related to global cultural competence, in the form of either before-and-after measures or comparisons among study abroad participants and nonparticipants in a public affairs program. Other professional fields have applied measures of cultural competency before and after to document the effectiveness of their study abroad programs (Ballestas \& Roller, 2013; Douglas \& JonesRikkers, 2001; Marx, 2011; Zhai \& Scheer, 2002), and public affairs should be engaging in this type of empirical research at the level of individual programs as well as more broadly.

At the level of individual faculty teaching courses with study abroad components, serving as group leaders of short-term study abroad, or advising students completing international internships, our research suggests that these faculty need to direct greater attention to systematic evaluation. Beyond individual course evaluations, programs should explore ways to link the assessment of study abroad experiences to their missions and student learning outcomes or competencies. Improved communication between the public affairs programs and central study abroad offices could also contribute to better assessment. Program departments can also request that centralized evaluations be customized by programs to the extent possible, in lieu of creating an additional evaluation system. On a grander scale, NASPAA could facilitate the development of an assessment instrument that would allow for collection of comparable data across programs.

Finally, if NASPAA is truly committed to cultural competency on a global scale, perhaps it is time to consider a standards-based expectation for some form of internationalization and assessment of students' global cultural competency. The standards imply this, but arguably a more explicit articulation is warranted, as standards should not be left to interpretation. We assert that global cultural competence is an essential, not merely optional or desirable, skill for the 21st-century public affairs professional. 


\section{ACKNOWLEDGEMENTS}

The authors would like to acknowledge the tremendous research support provided by Alyssa Napolitano.

\section{NOTES}

1. The membership list provided by NASPAA in October 2013 included 282 programs; however, only 275 e-mail addresses were functional within SurveyMonkey. Some e-mail addresses were rejected because the recipient had previously selected to opt out of SurveyMonkey; others were simply undeliverable.

2. With the data collected, we produced a quantitative and qualitative database using spreadsheet software. Considering the debate about the use of qualitative software (see MacMillan \& Koenig, 2004, p. 180; Crowley, Harré, \& Tagg, 2002), we opted not to use further data management software, as the spreadsheet software was a sufficient tool for organizing our survey and interview data.

3. For the purposes of this analysis, we collapsed the mission variable into two categories of either having an international reference in the mission (at the level of the school, program, or both) or not (by virtue of having no reference in the mission or having no mission). In relation to both a two-category measure (no study abroad opportunities vs. study abroad) as well as a three-category measure (no study abroad, external study abroad, or in-house study abroad), the relationship with an international statement in the mission is statistically significant at the .01 level.

4. Some programs did not provide a response to this question, thus percentages do not equal 100\%.

\section{REFERENCES}

Ballestas, H. C., \& Roller, M. C. (2013). The effectiveness of a study abroad program for increasing students' cultural competence. Journal of Nursing Education and Practice, 3(6), 125-133.
Black, H. T., \& Duhon, D. L. (2006). Assessing the impact of business study abroad programs on cultural awareness and personal development. Journal of Education for Business, 81(3), 140-144.

Cheney, R. S. (2001). Intercultural business communication, international students, and experiential learning. Business Communication Quarterly, 64(4), 90-104.

Corbin, J., \& Strauss, A. (2008). Basics of qualitative research (3rd ed.). Thousand Oaks, CA: Sage.

Creswell, J. W. (2003). Research design: qualitative, quantitative, and mixed methods approaches. Thousands Oaks, CA: Sage.

Crowley, C., Harré, R., \& Tagg, C. (2002). Qualitative research and computing. International Journal of Social Research Methodology, 5(3), 193-197.

Crowne, K. A. (2008). What leads to cultural intelligence? Business Horizons, 51(5), 391-399.

Deardorff, D. K. (2006). Identification and assessment of intercultural competence as a student outcome of internationalization. Journal of Studies in International Education, 10(3), 241-266.

Devereux, E. A., \& Durning, D. (2001). Going global: International activities by US schools of public policy and management to transform public affairs education. Journal of Public Affairs Education, 7(4), $241-260$.

DiBiaso, D., \& Mello, N. A. (2004). Multi-level assessment of program outcomes: Assessing a nontraditional study abroad program in the engineering disciplines. Frontiers: The Interdisciplinary Journal of Study Abroad, X, 237-252.

Dolby, N. (2007). Reflections on nation: American undergraduates and education abroad. Journal of Studies in International Education, 11(2), 141-156.

Douglas, C., \& Jones-Rikkers, C. G. (2001). Study abroad programs and American student world mindedness: An empirical analysis. Journal of Teaching in International Business, 13(1), 55-66.

Downey, G. L., Lucena, J. C., Moskal, B. M., Parkhurst, R., Bigley, T., Hays, C.,... Nichols-Belo, A. (2006). The globally competent engineer: Working effectively with people who define problems differently. Journal of Engineering Education, 95 (2), 107-122. 
Goldstein, S. B., \& Kim, R.I. (2006). Predictors of U.S. college students' participation in study abroad programs: A longitudinal study. International Journal of Intercultural Relations, 30(4), 507-521.

Horn, A. S., \& Fry, G. W. (2013). Promoting global citizenship through study abroad: The influence of program destination, type, and duration on the propensity for development volunteerism. Voluntas, 24(4), 1159-1179.

Institute of International Education. (2013). Open doors report on international educational exchange. Retrieved from http://www.iie.org/opendoors

Lindsey, E. W. (2005). Study abroad and values development in social work students. Journal of Social Work Education, 41(2), 229-249.

Long, T. B. (2012). Overview of teaching strategies for cultural competence in nursing students. Journal of Cultural Diversity, 19(3), 102-108.

MacMillan, K., \& Koenig, T. (2004). The wow factor. Preconception and expectation for data analysis software in qualitative research, Social Science Computer Review, 22(2), 179-186.

Marcotte, C., Desroches, J., \& Poupart, I. (2007). Preparing internationally minded business graduates: The role of international mobility programs. Journal of Studies in International Education, 9(3), 265-278.

Marx, H. (2011). Please mind the culture gap: Intercultural development during a teacher education study abroad. Journal of Teacher Education, 62(1), 35-47.

Mkandawire-Valhmu, L., \& Doering, J. (2012). Study abroad as a tool for promoting cultural safety in nursing education. Journal of Transcultural Nursing, 21(1), 82-89.

Murphy, J. P., \& Meyer, V. (2012). Going global: Strategies for study abroad at the School of Public Service, DePaul University, Chicago. Nonprofit Management and Leadership, 23, 137-151.

Norman-Major, K. A., \& Gooden, S. T. (Eds.). (2012). Cultural competency for public administrators. Armonk, NY: M. E. Sharpe.

Orahood, T., Kruze, L., \& Pearson, D. E. (2004). The impact of study abroad on business students' career goals. Frontiers: The Interdisciplinary Journal of Study Abroad, 10, 117-130.
Ruddock, H. C., \& Turner, D. S. (2007). Developing cultural sensitivity: nursing students' experiences of a study abroad programme. Journal of Advanced Nursing, 59(4), 361-369.

Ryan, S. W. (2010). Let's get them out of the country! Reflecting on the value of international immersion experiences for MPA students. Journal of Public Affairs Education, 16(2), 307-312.

Steir, J. (2003). Internationalisation, ethnic diversity and the acquisition of intercultural competencies. Intercultural Education, 14(1), 77-91.

Zhai, L., \& Scheer, S. D. (2002). Influence of international study abroad programs on agricultural college students. Journal of International Agricultural and Extension Education, 9(3), 23-29.

\section{ABOUT THE AUTHORS}

Nadia Rubaii is associate professor of public administration in the College of Community and Public Affairs at Binghamton University, State University of New York. Her research examines issues of diversity with an emphasis on enhancing cultural competence in professional public service. Her research also examines the challenges of applying U.S.-based standards of educational quality in a comparative context with a particular focus on Latin America.

Susan Appe is assistant professor of public administration at the College of Community and Public Affairs at Binghamton University, State University of New York. Her research centers on government-nonprofit relations, the evolution of the nonprofit sector in developed and developing countries, and the implications of international service learning in public affairs education.

Kerry Stamp is assistant director for study abroad in the Office of International Programs at Binghamton University, State University of New York, where she is also a doctoral student of public affairs. Her research areas of interest include diversity and inclusion in study abroad, and global service learning. 


\section{APPENDIX A}

\section{Survey Instrument}

Dear NASPAA Member Program Liaison:

The following short (7-question) survey regarding international opportunities for students in NASPAA member programs should take less than 2 minutes to complete. We appreciate your time and participation.

1. Which of the following degree programs does your department/college/school offer? (Check all that apply.)

$\square$ Masters of Public Administration

$\square$ Masters of Public Policy

$\square$ Masters of Public Affairs

$\square$ PhD or DPA (in Public Administration, Public Policy, or Public Affairs)

$\square$ BA or BS in Public Administration/Public Service/Public Affairs

$\square$ Other

For the remaining questions, please focus only on the master's-level degree programs in public affairs (MPA, MPP, MPAff, or related degree). These will be referred to simply as "MPA/MPP programs" but should be understood to include other master's programs encompassed by NASPAA's scope.

2. Is your MPA/MPP program NASPAA-accredited?

$\square$ Yes

$\square$ No

3. Where, if at all, do the terms "international," "global," or "world" (including variations on those terms) appear in your mission statement?

$\square$ In the mission of the college/school/department and the MPA/MPP program

$\square$ In the mission of the college/school/department only

$\square$ In the mission of the MPA/MPP program only

$\square$ Not at all

$\square$ Not sure

We do not have a mission statement 
4. Which of the following statements best reflects the message conveyed to MPA/MPP students about study abroad?

$\square$ It is a mandatory component of the program

$\square$ It is a recommended aspect of the program for all students

$\square$ It is a recommended aspect of the program for some students, depending on their interests

$\square$ It is an option for students

$\square$ It is not an option for students at the present time but the program is considering developing options (skip to end and THANK YOU)

$\square$ It is not an option for students and we have no plans to develop options (skip to end and THANK YOU)

For the purposes of the following questions, please consider any study abroad opportunities which are administered entirely or in part at the level of the MPA/MPP program, that is, where MPA/MPP faculty or staff oversee the program design, establish program requirements, evaluate student progress, or have similar levels of influence, even if other aspects of the study abroad program are administered by a central office outside the MPA/MPP program.

5. Which of the following statements apply? (Check all that apply.)

$\square$ The MPA/MPP program offers full-semester or full-year study abroad programs

$\square$ The MPA/MPP program offers short-term (less than a semester) study abroad programs

$\square$ MPA/MPP study abroad programs are available only to MPA/MPP students

$\square$ MPA/MPP study abroad programs are open to graduate students in other majors

$\square$ MPA/MPP study abroad programs are open to undergraduate students as well

$\square$ The MPA/MPP program does not offer any study abroad programs in-house (skip to end and THANK YOU)

6. Do any of your MPA/MPP study abroad opportunities integrate international service learning?

$\square$ Yes

$\square$ No

Please provide the name(s) and e-mail contact information of faculty/staff who lead the study abroad program(s) in your department: 


\section{APPENDIX B}

\section{Interview Questions}

1. According to the survey responses, your program is (required, encouraged, optional) and is available to (student types) and you have programs of (length). Is that correct?

2. How many international programs do you have? How many of those have a service-learning component? In what countries are they located? For each program, can you tell me a little bit about how and when it started?

3. Please describe the basic program characteristics.

4. Can you explain the relationship and roles of you, other faculty or staff in your public affairs program, and a central university office for international programs?

5. Does the institution or program collect data on student participant characteristics (age, race, gender, first-generation student, etc.)? Has anyone analyzed it?

6. How do you define and measure program effectiveness or success?

\section{Skip to question 11 for programs without international service learning (ISL). For those that have ISL,} continue with these questions:

7. To what extent are the service partners and service projects consistent each time or do they vary? What was done to develop and maintain the service-partner relationships? Please provide 2 or 3 examples of the types of service projects your students have engaged in as part of this program.

8. Do you have any formal relationship with a university in that country as part of this program? If so, what is their role and how did you identify that partner? Do you have a reciprocal relationship to provide international service learning opportunities for students from that university or from another university?

9. There is considerable literature on the ethical challenges associated with international service. To what extent and in what ways are these issues addressed by the program before, during, and/or after the study abroad experience?

10. Based on your experience with this program, what lessons have you learned about international service learning and what advice would you offer to others?

11. Based on your experience with study abroad programs, what lessons have you learned and what advice would you offer to others? 